tion between total pethidine dose and norpethidine concentration was found. In renal impairment norpethidine elimination is prolonged, leading to a greater accumulation.

Despite mounting evidence against pethidine as a first line analgesic in sickle cell crisis its use persists. We find that patients seem to prefer intramuscular pethidine despite its short duration of action and poor analgesia. This preference was also stated by patients' representatives (Sickle and Thalassaemia Association of Counsellors, Cardiff, September 1991). Apparent ease of administration and doctors' familiarity with the drug further perpetuates this legacy. Pethidine should not be used in patients who have a history of seizure after pethidine or renal impairment. ${ }^{23}$ Daily doses exceeding $25 \mathrm{mg} / \mathrm{kg}$ are likely to produce excitatory effects due to norpethidine toxicity.

1 Mitchell A, Fisher AP, Brunner M, Ware RG, Hanna M. Pethidine for painfu crisis in sickle cell disease. $B M \mathcal{F}$ 1991;303:249.

2 Kaiko RF, Foley KM, Grabinski PY, Heidrich G, Rogers AG, Inturrisi CE et al. Central nervous system excitatory effects of meperidine in cancer patients. Ann Neurol 1983;13:180-5.

3 Tang R, Shimomura SK, Rotblatt $M$. Meperidine-induced seizures in sickle cell patients. Hospital Formulary 1980;15:764-72.

4 Reynolds F, Beckett $\mathrm{AH}$. The determination of bupivacaine, lignocaine and mepivacaine in human blood. Br 7 Pharmacol 1968;20:704-6.

5 Szeto HH, Inturrisi CE, Houde R, Saal S, Cheigh J, Reidenberg MM. Accumulation of normeperidine, an active metabolite of meperidine, in patients with renal failure or cancer. Ann Intern Med 1977;86:738-41.

(Accepted 10 March 1992)

\section{Prevalence of potential pathogens in cervical canal before termination of pregnancy}

\section{Mike Cohn, Peter Stewart}

Department of Obstetrics and Gynaecology, Northern General Hospital, Sheffield S5 7AU Mike Cohn, research registrar Peter Stewart, consultant

Correspondence to: Dr M Cohn, Department of Obstetrics and Gynaecology, Leicester Royal Infirmary, Leicester LE1 5WW.

$B M \mathcal{F}$ 1992;304:1479 canal of women requesting terminations in Sheffield.

\section{Patients, methods, and results}

Pelvic infection is a complication of termination of pregnancy. ${ }^{1}$ The risk is increased if Chlamydia trachomatis or other potential pathogens are present in the cervical canal before the abortion. ${ }^{2}$ We report the prevalences of five potential pathogens in the cervical

We performed a retrospective analysis on the microbiological results of endocervical swabs taken from 1784 consecutive women requesting termination of pregnancy at this hospital. Neisseria gonorrhoeae was isolated from three women, $C$ trachomatis from 155 , Mycoplasma hominis from 315, Ureaplasma urealyticum from 340, and Trichomonas vaginalis from 30. One or more of these micro-organisms were isolated in 652 women.

For the analysis, if either $N$ gonorrhoeae or $C$ trachomatis was isolated the patient was deemed to be at a "high risk" of developing pelvic infection after termination whereas those harbouring $M$ hominis, $U$ urealyticum, or $T$ vaginalis were thought to be at "moderate risk." As marital status, age, and parity are likely to be related to risk a multivariate approach was taken. A cumulative logic model ${ }^{3}$ was fitted to the data with the SAS statistical package with the dependent variable as infection (none, moderate risk, high risk) and the explanatory variables as marital status (single, married, divorced, or separated), age ( $\leqslant 24,25-29$, $30-34, \geqslant 35$ ), and parity (primigravid, nulliparous other than primigravid, multiparous).

The model of best fit included all three of the explanatory variables; the fit became significantly poorer (at the $5 \%$ level) when any of these variables was dropped from the model. The final model showed that
Sensitivity ${ }^{\star}$ and efficiency† of selective testing for endocervical micro-organisms before termination of pregnancy

\begin{tabular}{|c|c|c|c|c|c|}
\hline \multirow[b]{2}{*}{ Patient characteristic } & \multirow{2}{*}{$\begin{array}{c}\text { No }(\%) \\
\text { women } \\
\text { tested }\end{array}$} & \multicolumn{2}{|c|}{ High risk infections } & \multicolumn{2}{|c|}{ All infections } \\
\hline & & Sensitivity (\%) & Efficiency (\%) & Sensitivity (\%) & Efficiency (\%) \\
\hline All women & $100 \cdot 0$ & $100 \cdot 0$ & $1 \cdot 00$ & $100 \cdot 0$ & $1 \cdot 00$ \\
\hline Single & $71 \cdot 1$ & $82 \cdot 8$ & $1 \cdot 16$ & $78 \cdot 8$ & $1 \cdot 11$ \\
\hline Multiparous & $43 \cdot 3$ & $39 \cdot 2$ & 0.90 & $40 \cdot 1$ & 0.92 \\
\hline Aged $<25$ years & $66 \cdot 2$ & $77 \cdot 7$ & $1 \cdot 17$ & $72 \cdot 1$ & 1.09 \\
\hline Single, multiparous & $16 \cdot 9$ & $21 \cdot 6$ & 1.28 & $20 \cdot 5$ & $1 \cdot 21$ \\
\hline Single, aged $<25$ years & $59 \cdot 7$ & $72 \cdot 6$ & $1 \cdot 22$ & $67 \cdot 3$ & $1 \cdot 12$ \\
\hline
\end{tabular}

$\star$ Sensitivity= No detected/No infected $\times 100$. the chance of being at high risk of pelvic infection was increased for single women (adjusting for age and parity), those aged under 25 (adjusting for marital status and parity), and multiparous women (adjusting for marital status and age).

\section{Comment}

This large study showed that potential pathogens are found in the endocervical canal of an appreciable proportion of women requesting termination of pregnancy in Sheffield, thereby supporting the findings of other small studies in the United Kingdom. ${ }^{4}$ It also confirmed that such micro-organisms are more frequently isolated from young single women.

If $C$ trachomatis was present in the cervical canal before termination there was a $20-25 \%$ risk of the woman developing postabortion pelvic infection. ${ }^{2}$ This would have caused the woman discomfort and distress and might have required a further admission to hospital. A few of these women would experience long term subfertility and pelvic pain. ${ }^{5}$ Screening every patient requesting a termination would add about $£ 8.00$ to the cost of each abortion. However, the cost of treating women with established postabortion infection and of the long term sequelae should be set against this. Furthermore, by identifying infected women their partners can be tested and if necessary treated, thereby reducing the chances of the woman being reinfected and the pool of infected subjects within the population.

As cervical infections are more common in certain groups it would be possible to introduce selective screening to reduce the costs. The table illustrates the sensitivity and efficiency of different policies. If all single women under the age of 25 were tested only $60 \%$ of the population would be screened but $73 \%$ of infected subjects would be detected. Furthermore, most patients for whom subsequent fertility is most important would be screened.

We recommend that all patients requesting termination of pregnancy are screened for potential endocervical pathogens and that when these are detected appropriate antibiotics are prescribed at the time of the abortion. If resources are limited a selective policy could be introduced.

\section{We thank Carol Jaeger for statistical advice.}

\footnotetext{
Frank PI, Kay CR, Wingrave SV, Lewis TL, Osborne J, Newell C. Induced abortions and their early sequelae. $\mathcal{F} R$ Coll Gen Pract 1985;35:175-80.

2 Qvigstad E, Skaug K, Jerve F, Fylling P, Ulstrup JC. Pelvic inflammatory disease associated with Chlamydia trachomatis infection after therapeutic abortion. A prospective study. British foumal of Venereal Diseases 1983;59. 189-92.

3 Agresti A. Categorical data analysis. Chichester: Wiley, 1990:332-6.

4 Ridgway GL, Mumtaz G, Stephens RA, Oriel JD. Therapeutic abortion and chlamydial infection. BMF 1983;286:1478-9.

Heisterberg L. Pelvic inflammatory disease following induced first-trimester
} abortion. Dan Med Bull 1988;35:64-75. 